\title{
Design and use of crowdsourcing geographic data collection system during the monitoring phase of environmental impact assessment reports
}

\author{
Maraş E.E. ${ }^{1 *}$ and Canıberk M.2 \\ ${ }^{1}$ Samsun University, Department of Flight Training, Vocational School of Civil Aviation, 55080 Canik, Samsun, Turkey \\ ${ }^{2}$ General Directorate of Mapping, Photogrammetry Dept., 06590, Ankara, Turkey \\ Received: 12/03/2021, Accepted: 20/05/2021, Available online: 26/05/2021 \\ *to whom all correspondence should be addressed: e-mail: erdem.emaras@samsun.edu.tr \\ https://doi.org/10.30955/gnj.003595
}

\section{Graphical abstract}

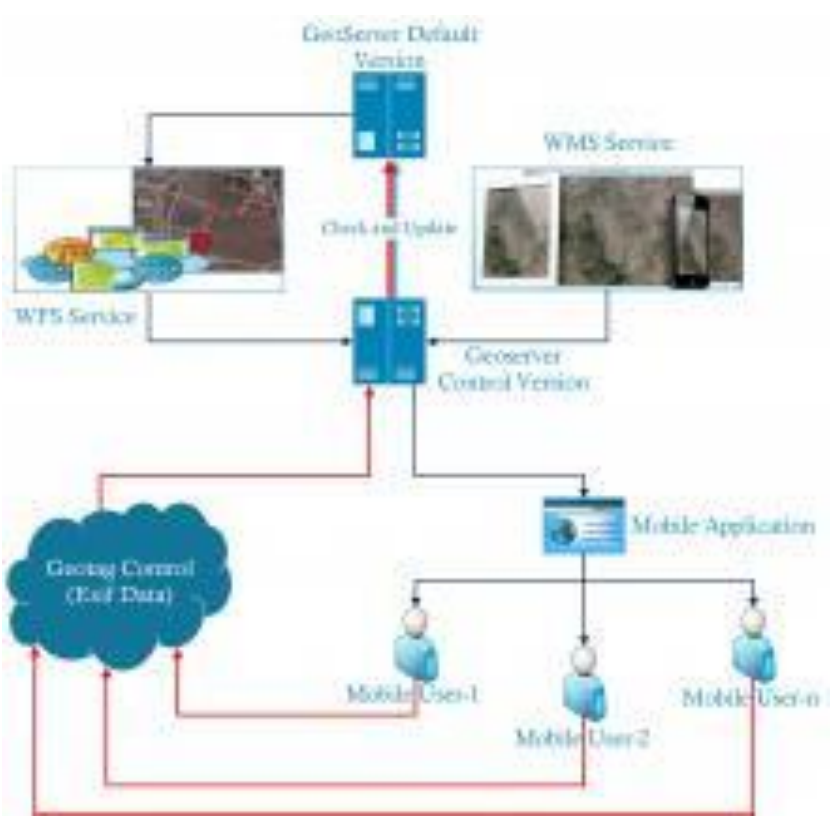

\section{Abstract}

When the whole earth is considered as a geographic place, it is clearly seen that the physical and social processes in the Earth's crust have direct or indirect connection with geography. In this century named information era, it is vital to find new solutions to people's problems by getting different results from gathering, providing, and querying information.

Geographic information systems are frequently used in the preparation and implementation stages of environmental impact assessment (EIA) projects. How-ever, the failure to use spatial data effectively during the monitoring phase, which is the final step of the assessment process, causes the inability to determine whether the activities undertaken in the report are implemented. This situation causes EIA reports and activities to be questioned or even not accepted by the public.
By inter-organizational data sharing, geographical data needs can be met and duplicate data productions can be avoided. However, the problem of updating the geographical data provided always comes out as the real problem. At this point, there are approaches that are defined as Crowdsourcing which refers the way of solving the problems of the institutions by utilizing the knowledge and experience outsourced. The most important institutional concern regarding crowdsourcing and geographical data extraction reveals itself as data consistency and accuracy.

With the system developed within the scope of this study, the status of EIA projects in implementation with the development of the project will be effectively controlled with the participation of the administration and the public. A crowdsourcing-based system has been prepared and introduced to ensure the participation of the public. With this study, the development of the project and the problems experienced during the monitoring phase can be controlled. Thus, it will be ensured that any negative situation that could be experienced will be prevented or minimized in a way that will not harm the environment.

Keywords: Crowdsourcing, database updating, data generation, geographic databases, GIS.

1. Introduction

As a requirement of sustainable development, it is necessary to determine the negative effects that activities can have on the environment at the very beginning and to prevent them before they occur. Identifying these measures and thus ensuring the sustainability of development by preserving natural and cultural assets is important for our world, which has been experiencing a shortage of natural resources in recent years.

Since the 1970s, the environmental problems being discussed and evaluated at the international level have also been domestically perceived to a great extent, especially in developed countries. Intensive efforts to first solve these problems and then more generally to protect and improve the environment have entered the political agendas of 
many nations (Anett et al., 2014). In the previous struggles to address existing pollution, it was understood that preventing pollution before it occurs is a better method because of the difficulty of removing pollution from the environment and the fact that this is costlier.

For this reason, environmental impact assessment (EIA) is a necessity for activities related to natural resource use and activities that are expected to have negative effects on the environment (Peker, 1996). The administrative and technical principles to be followed in EIA processes in Turkey were determined by the Environmental Impact Assessment Regulation prepared based on Environment Law No. 2872.

An EIA is a set of works to be carried out to determine the positive and negative environmental effects of projects that are planned to be implemented, to select the measures to be taken to prevent negative effects or to minimize them in a way that will not harm the environment, to determine the selected location and technology alternatives, and to monitor and control the implementation of projects (Anett et al., 2014).

Along with economic and technological developments, the developments in geographic information systems (GIS) have gradually increased the usage area and rate of digital maps and have led them to become one of the most important information technology tools of the last century, used by many institutions and organizations (Sivrikaya et al., 2010). In addition, GIS has been used frequently in the management, analysis, and visualization of very large amounts of data and information in different planning studies using spatial data (Agapiou et al., 2015).

The most important element in GIS studies is the integration of the collected attribute data with the spatial data (Işcan and Ilgaz, 2017). In addition to collecting data, it is also important to keep it up-to-date. Geographic data production is not a process that only experts and professionals can perform today. Amateur Internet users also contribute geographic data via online systems. The generation of geographic data by amateur users is defined as voluntary geographic information. Thus, the concept of crowdsourcing, used in many different disciplines, can also be used in GIS studies.

With the forecasting and prevention strategy based on the decisions to be made as a result of the EIA, it is possible to foresee problems and take precautionary measures for projects that will harm the environment in different ways, as well as addressing the economic and social costs that may arise from the subsequent environmental impacts of those activities. According to this strategy, activities subject to an EIA can contribute to economic and social development only if they do not cause environmental damage (Ekin, 2000).

An EIA can be described as a monitoring and assessment process that starts before the activity begins and continues after the activity ends, when the construction phase and its impacts are observed. Geographic data are required in all of these phases. In an EIA, the supply and the quality of spatial data are crucial. The obtained results will be directly proportional to the quality of the data. Many researchers have suggested that GIS is a very useful tool in EIAs and have predicted that its use will rapidly become widespread (Yıldırım et al., 2016).

Geographic Information Systems (GIS) are systems used for storing, organizing, querying, analyzing, and presenting spatial data in the same environment. Environmental Impact Assessment (EIA), an effective environmental management tool, is a systematically structured process that examines the environmental impacts based on a proposed project.

Considering the spatial characteristics of many natural or socio-economic environmental impacts, GIS can be an important tool that can be used in all stages of the environmental impact assessment process. In terms of GIS in environmental impact assessment, the availability and quality of spatial data are critical. The quality of the data will also reveal the value of the results. The most important feature of GIS is that it enables to obtain of successful spatial analyses and, accordingly, reliable results. The analytical potential of GIS is particularly valuable in the context of EIA. Many GIS applications in the EIA use basic GIS functions such as length and area measurement and map production.

Crowdsourcing, utilizing masses or crowds as a source, was introduced in the literature in 2006 by Jeff Howe's Wired article, "The Rise of Crowdsourcing". This concept, also referred to as "utilization of the crowd", can also be described as the contribution of everyone with an Internet connection to productivity and the resolution of organizational problems (Howe, 2006).

Eric S. Raymond's approach wherein any problem can be solved when it is addressed by a great number of people forms the basis of crowdsourcing. In addition, it is commonly assumed that a large and diverse labor force is able to provide better solutions than the most talented and skilled homogeneous workforce (Raymond and O'Reilly, 1999). That is why crowdsourcing will be very important for many sectors in the future. The basis of crowdsourcing is formed by people who want to feel themselves belonging to a group or community or by volunteers who seek to create added value through their hobbies or interests. This reduces the costs for organizations such as geographic information organizations, as well as for different sectors, and it can make failure costless (Annad et al., 2017).

As with any system, crowdsourcing practices also have negative effects and consequences. The disadvantage in this application is the creation of a mass in line with the purpose of the application. Project's producing wrong results in consequence of a formation of inappropriate mass is an inevitable outcome. Especially the accuracy and up-to-dateness of the data provided to the system by the mass is the most important disadvantage in this study.

In general terms, the disadvantages of all crowdsourcing applications can be summarized as follows (Sloane, 2011).

- Data quality

- Technical knowledge inadequacy of the mass 
- Data confirmation

- Lack of motivation of the mass

Despite the fact that advances in technology have increased the number of studies on crowdsourcing-based geographic information systems, there are questions about the quality of the data collected by volunteers and how to ensure the volunteers' motivation. What encourages the crowd to come up with solutions is making the crowd motivated within the scope of the project. There are three basic elements that motivate the crowd. The first is that people are psychologically happy with the solutions they produce, and the other is some financial returns they receive as a result of their contributions. Finally, it is observed that the crowd is motivated by communicating with qualified people and improving themselves as well as the financial rewards they have received (Pang and Liu, 2016).

GIS and geographic databases constantly need up-to-date and accurate geographic information during their transition to functionalization and, if necessary, during their operational period (Önder, 2000). The necessary data can be collected in two ways: firsthand collection or collection from another source. Regardless of the method used, firsthand geographic data collection is a very expensive, time-consuming, and often undesirable process today. On the other hand, data collected from another source may be insufficient in terms of accuracy and up-todateness. Given these two problems, it is often preferred to collect data from other sources due to the need for upto-date geographic data. However, the accuracy problem in this method should always be considered in the control stages.

Crowdsourcing is also frequently used in geographic data production today. In this study, it is revealed that the data accuracy control process to be applied while using this method can be realized by means of the properties existing in digital images taken with smartphones. With this approach, it is aimed to solve the accuracy problems of the users who need data.

\section{Research significance}

With crowdsourcing, large projects can be broken down into small pieces and entire projects can be completed by making contributions that participants consider as very simple operations for themselves. Thus, large and complex steps can be completed effectively in a short time.

Today, with the development of satellite and camera systems, easy access to those systems, and the availability of GNSS (Global Navigation Satellite Systems) receivers on almost every smartphone, geographic data can be easily obtained. It is further expected that the problem of data being up-to-date in the processing, analysis, and examination stages of geographic data in national-scale projects will be eliminated by the use of crowdsourcing. GNSS is a navigation system that is used to determine instant and high accuracy location, speed, and time in a global coordinate system with the help of signals received from satellites in all weather conditions and throughout the world (Yıldız and Kahveci, 2010). Today, three systems operate as the main service provider in global positioning systems, and these are; USA (GPS), Russia (GLONASS), and the European Union (Galileo).

Monitoring is the last step in the EIA process and it takes longer than other processes. In addition to being a scientific document, an EIA report entails certain commitments (Persada et al., 2015). During the monitoring process, it is tested whether these commitments in the EIA report have been fulfilled. There are no specific scientific methods that can be used in the monitoring step, as in the scope and elimination steps (Gökalp, 2020). However, it is imperative that a mechanism be introduced to ensure that the conditions laid down in an EIA report and the decision itself are actually implemented as decided (Sluser et al., 2015).

Today, spatial knowledge forms the basis of all kinds of planning work (Despotakis and Economopoulos, 2007). For this reason, basing planning studies on correct and up-todate geographic data is the most important factor in making sound decisions. The applicability of planning depends, of course, on the availability and quality of knowledge (Önder, 2000), and one of the most important elements of quality information is being up-to-date.

In this study, with the proposed method, it is aimed to effectively conduct a monitoring process that spans a long period time to ensure the participation of multiple parties and to reduce the workload of the administration with a control authority. At the same time, with this proposed method, all the impacts after the EIA will be continuously monitored beyond the routine steps of the control mechanism, allowing the central decision-making mechanism to produce objective and holistic decisions.

\section{Aim of the study}

It is known that people have access to geographic data via many applications with smartphones and tablets. Users most often only use geographic data to solve their personal needs, but a considerable number of users contribute to the geographic data with personal data entries. With the ease of Internet access and the widespread use of mobile technologies, many people now share their geotagged files with the world and also benefit from the files shared by other people. Thus, the Internet emerges as an environment in which spatial data are gathered, shared, and developed (Goodchild, 2007).

The standards for geographic data quality are defined in ISO 19157 with six quality criteria: completeness, consistency, spatial accuracy, timeliness, thematic accuracy, and usability (ISO, 2013). Spatial databases are sustainable to the extent that these geographic quality standards are met. The addition of information obtained through crowdsourcing to a dataset entirely produced by specialists may initially cause concerns about accuracy and consistency. The analysis of such information may not always be possible, or it may be costly (Antoniou and Skopeliti, 2015). Therefore, without the reference dataset, different methods are needed to determine the quality or correctness of geographic data obtained by crowdsourcing (Goodchild and Li, 2012). Due to the complexity of this 
whole process, it is indicated that the quality of data cannot be checked in roughly half of the studies in which the geographic data were obtained by crowdsourcing (Hidalgo and Thiel, 2015). Therefore, researchers need to develop methods for improving data production processes.

The most important point that makes this study different is that the geographic data obtained by crowdsourcing is passed through a control mechanism. In this way, data quality and data accuracy control, which are the most important problems of crowdsourcing geographic data collection studies, will be automatically provided.

\section{Materials and methods}

The update system created within the scope of this study is designed to work on smartphones or tablets with the Android operating system. The number of Android operating system users is increasing day by day, due to Android's many outstanding features, especially with its open source code. The vast majority of phone manufacturers use the Android operating system for the phones they produce.

Android Studio is an IntelliJ (Java language application development interface)-based integrated development environment (IDE) developed by Google for Android applications. Android Studio offers many possibilities for programmers who want to develop applications on devices with the Android operating system. Google also recommends this IDE (Budiu, 2013) to Android developers.

Web Feature Service (WFS) is the standard that allows for access, display, and editing of the data stored in vector format on servers by WFS-like URL requests (Vretanos, 2005). As the data format, other OGC standards such as Geography Markup Language (GML) or GeoJSON formats are used. The workflow for displaying the geographic data used in this study as per WFS and displaying it in an Android application is presented in Figure 1.

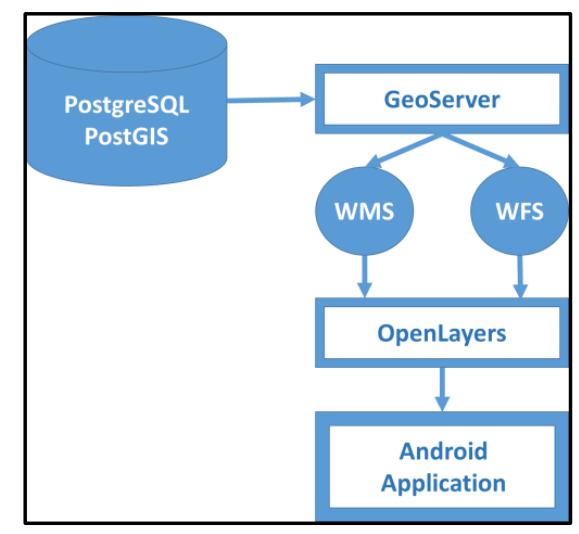

Figure 1. Publication of geographic data

PostgreSQL is an object-relational database management system (Borkowski et al., 2016). PostGIS allows the use of geographic details in the PostgreSQL object-relational database. With PostGIS, the PostgreSQL server works as a spatial server for GIS. PostGIS also supports the OGC "Simple Features for SQL" standard (Strobl, 2016). PostGIS is used by a large number of open source map servers and has extensive user support (Ballatore et al., 2018).
GeoServer is a Java-based and open source Web map server software that allows users to view and edit spatial data. GeoServer also supports open standards developed by OGC, such as WFS, WMS, and WCS (Landeta et al., 2019). GeoServer was developed by a special group of organizations from different parts of the world and is supported by a large number of parties. In this way, the software is kept up-to-date and is customized quickly and easily in line with the requirements.

OpenLayers is a JavaScript library that allows spatial data to be displayed on web browsers independently of server variables (Ballatore et al., 2018). It gives the web browser the ability to perform operations such as panning or zooming on the maps. The OpenLayers library also supports industry standards such as WMS and WFS. Although the OpenLayers library comes embedded in the GeoServer software, it can be used externally in the design phase of web pages. In addition to navigational tools on the map, there are also tools in the library that allow for some arrangements on the layers.

In order to obtain geographical coordinate information from image files sent by users, an application was developed with Microsoft Visual Studio 2012 in the C\# programming language. The MetadataExtractor library is used to read the EXIF information from the images.

Different applications, such as those in earth sciences, natural resource management (Wang et al., 2017), environmental protection (Ghodeif et al., 2013) urban and regional planning (Abdelfattah and Kumar, 2014; Dihkan et al., 2018), water resources management (Mouratidis et al., 2010), defense, transportation, tourism, statistics, and education, require geographic data because they need analysis at regional or more national levels (Başaraner and Selçuk, 2004). Spatial data are generally resolution- or scale-dependent and should be analyzed and presented at the resolution or scale best suited for the modeled events and processes (Weibel and Dutton, 1998).

Database update works are mostly done with photogrammetric methods and field studies. Hanson and Wolff (2010) stated that the systems using these methods are generally expensive and time-consuming, and therefore they fail to respond effectively to update requests. For large-scale databases, Müller and Heipke (2009) achieved a $65.5 \%$ success rate with the method that they developed with semi-automated updating and a control model using aerial photographs at $10 \mathrm{~cm}$ resolution. However, we can foresee that it will be difficult to implement it on a country basis because the method that they applied will require the institutional database to be kept up to date with institutional possibilities.

It is a known fact that the geographical data used in environmental impact assessment studies should be kept up-to-date as well as their collection. With this study, it is estimated that significant contributions can be made to ensure data update.

\section{A case study}


First, it is necessary to design an infrastructure that can collect geographic data with the crowdsourcing method. For this purpose, vector data transmission from a test database and the supporting of the broadcast with a satellite substation should be realized. In addition, an application for accessing data on Android-based mobile platforms (tablets or smartphones) and an algorithm to control the data coming from the application should be developed.

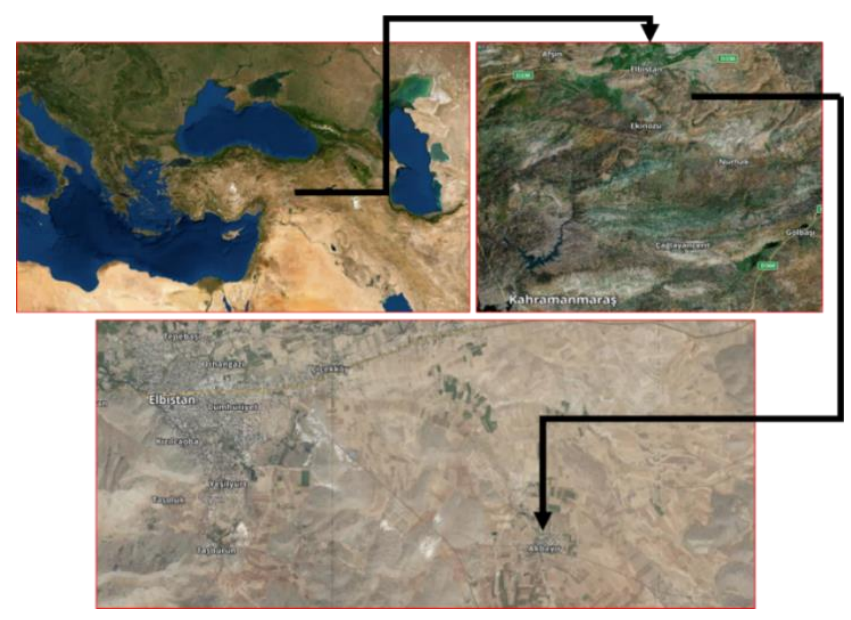

Figure 2. The general view of the study area

In the case study conducted within the scope of this work, the EIA report prepared for a thermal power plant in 2018 is discussed. Within this scope, after the commissioning of the power plant, geographic data including data for the power plant area, stripping site, ash waste area, and open coal mine area were prepared. An overview of the study area is shown in Figure 2 and a map of the areas where the designated units are planned is presented in Figure 3.

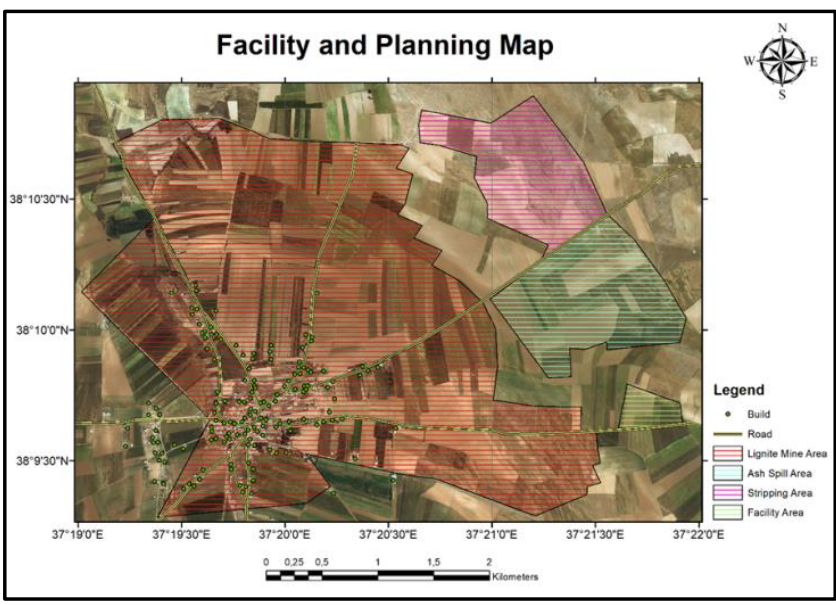

Figure 3. Units planned with the project

\subsection{Vector data publication from databases}

The geographic data to be published are classified as point, line, and area geometry structures obtained from the EIA report prepared for the thermal power plant and stored in Shape format.

Web Mercator (EPSG: 900913) is the most popular and current projection used today for web map providers (such as Google Maps or OpenStreetMap) for spatial displays on the web. In this projection, even if the geographical coordinates are based on the WGS84 ellipsoid, the calculations are made as if they were earth-based in terms of simplicity and rapid imaging (Battersby et al., 2014).

Thus, GeoServer software automatically converts the data into Web Mercator projections when vector data are placed on maps, such as in Google, Bing, or OpenStreetMap, and ensures that the data are displayed in the correct positions on the maps.

The data in the form of area, line, and point layers are loaded into PostGIS software with pgShapeLoader software. GeoServer was connected with the PostGIS software, making the vector data available in the GeoServer software. As a result, the prepared geographic data are now offered as WFS and the satellite images of Google are now offered as WMS.

\subsection{Access to geographic data with the Android app}

Definition of the OpenLayers map to be displayed with the geographic data is done by the code "map = newOpenLayers.Map ('map', options)". With this code a basic "map" object is defined and consequently the map on which the data will be displayed is defined.

The prepared vector data were later published as WFS using the GeoServer software. After the release of these services, the definition of the satellite image to be used as a base in the web application was made. By means of this definition, the map to be displayed as a base can be assigned via Google Maps, Open Imaginery, or any satellite image, Furthermore, if Google Maps is to be used, it can be determined which map will be assigned among satellite, terrain, and mixed maps (var SATELLITE = newOpenLayers.Layer.Google ("SATELLITE", \{type: G_SATELLITE_MAP, sphericalMercator: true\})).

Each basic map and WFS layer in the created OpenLayers interface is displayed using the following codes. Each layer found here will appear in the layer selection section in the Android application interface. An example of the application code is shown in Table 1.

Table 1. Adding vector and raster layers with OpenLayers

\begin{tabular}{cc}
\hline Adding a vector layer & Adding a raster layer \\
\hline $\begin{array}{c}\text { constvector }= \\
\text { newVectorLayer(\{ }\end{array}$ & constraster = newTileLayer(\{ \\
\hline source: vectorSource, & source: newGoogleMaps(\{ \\
\hline style: new Style(\{ & imagerySet: 'Aerial', \\
\hline stroke: newStroke(\{ & key: '123456' \\
\hline color: 'rgba(0, $0,255,1.0)$ ', & \}$)$ \\
\hline width: 2$\})$ & \}$) ;$ \\
\hline$\})$ & \\
\hline \});
\end{tabular}

The Java code prepared with OpenLayers is integrated into a mobile application developed in the Android Studio environment. Users with the mobile application can thus access the published data with a base and can change data attributes or geometry. The main screen of the application and the views related to the layer display and the access screens for the attributes are presented in Figure 4. 

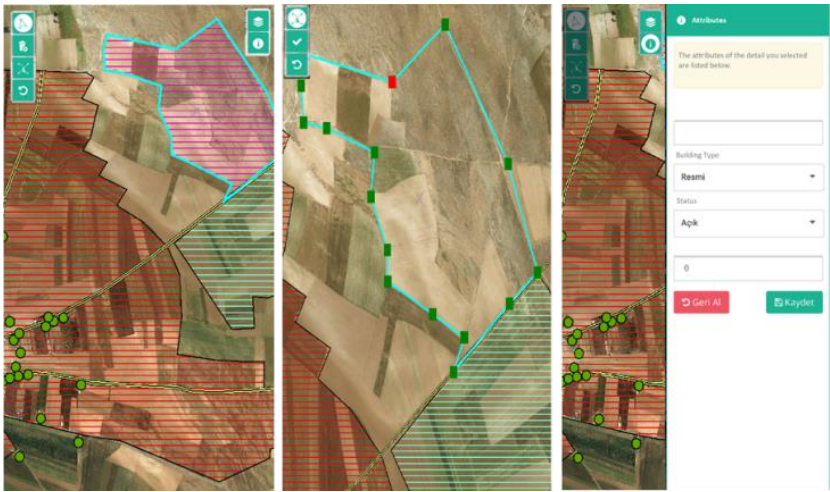

Figure 4. Application main screen, layer display, displaying details of vertices and details of attributes

\subsection{Accessing EXIF information of the photos from users}

The mobile application requires users to save changes and then upload a photo to the system. This step may be regarded as a necessity or it may be left to the user's initiative. If users upload images after data entry, some information can be obtained by means of information called EXIF in the photographs. This information includes the characteristics of the device and camera used, coordinate and magnetic azimuth information, and metric information about the photo. In the application developed for accessing this information, the "MetadataExtractor" library was used. In this way, access to information embedded in a displayed photograph is ensured.

Although a user screen is not needed since the application will not work with user interaction, an image of a user interface designed for use in test runs is shown in Figure 5.

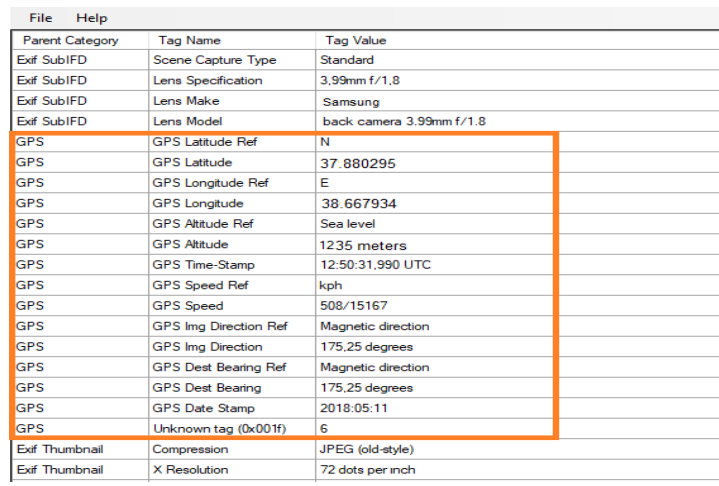

Figure 5. User interface developed for accessing EXIF data and GPS information

Table 2. EXIF information of the photographs

\begin{tabular}{cccc}
\hline & Lignite Mine Area & Ash Spill Area & Facility Area \\
\hline Latitude & $37.347830 \mathrm{~N}$ & $37.353386 \mathrm{~N}$ & $37.360192 \mathrm{~N}$ \\
\hline Longitude & $38.159327 \mathrm{E}$ & $38.180930 \mathrm{E}$ & $38.160698 \mathrm{E}$ \\
\hline Height from Sea Level & $1242 \mathrm{~m}$ & $1238 \mathrm{~m}$ & $1259 \mathrm{~m}$ \\
\hline Camera Magnetic Azimuth Angle & $175.25^{\circ}$ & $32.82^{\circ}$ & $122,76^{\circ}$ \\
\hline GPS Date Stamp & 11.05 .2019 & 02.06 .2019 & 26.06 .2019 \\
\hline
\end{tabular}

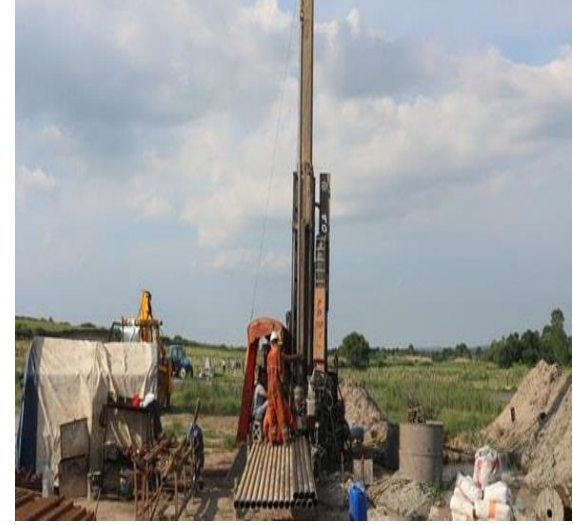

Figure 6. Uploaded image of lignite mine area

Many photos (over a thousand) were uploaded to the system using the application developed as part of this study at various times and by various users. Since most of the photographs have EXIF information, latitude-longitude and date information could be reached. Developments and changes in the project area can be monitored temporarily by using these photographs. The photos uploaded to the system are shown in their geographical coordinates and locations in the project area. In this way, a sustainable control mechanism can be established during the monitoring and control process of an Environmental
Impact Assessment project, which is one of the most important measures.

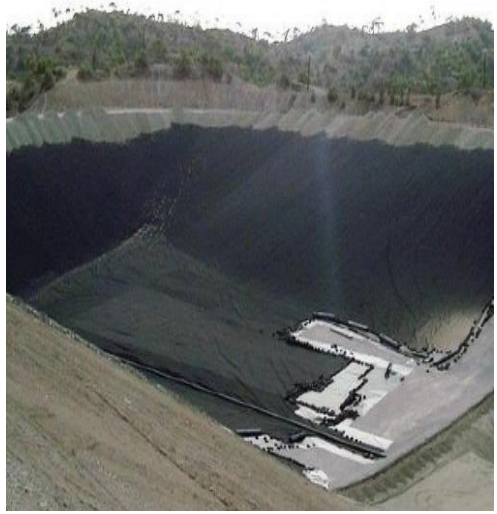

Figure 7. Uploaded image of ash spill area

Images taken at different times and uploaded to the system by users are shown in Figures 6-8 and the EXIF information obtained from the images is presented in Table 2.

\subsection{Integration of project data and data obtained using crowdsourcing}

The integration of the geographic data published within the scope of the study and the photos provided by the users was carried out in two stages. In the first step, pictures 
containing EXIF information of the photographs and having coordinates of any location in the project area were automatically determined. In this way, data that were inaccurate or outside the project area were automatically excluded from the evaluation. The project's region (open coal mine site, ash landfill, etc.) was identified in the second stage based on the pictures obtained. During the creation and monitoring phases of the EIA project, the successful use of the data collected through crowdsourcing was ensured in this way. In Figure 9, the information of a picture whose classification has been completed is presented on the application screen.

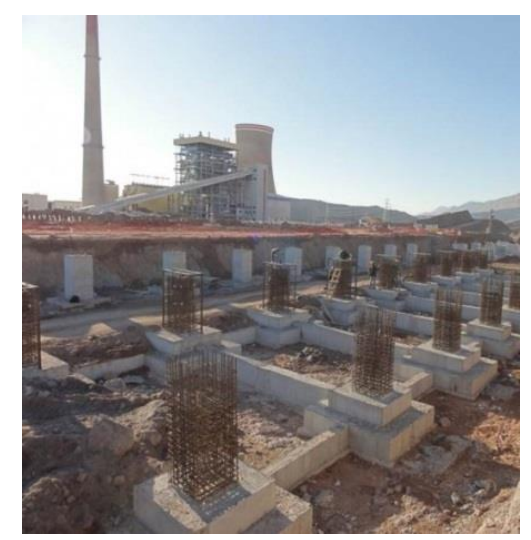

Figure 8. Uploaded image for facility area

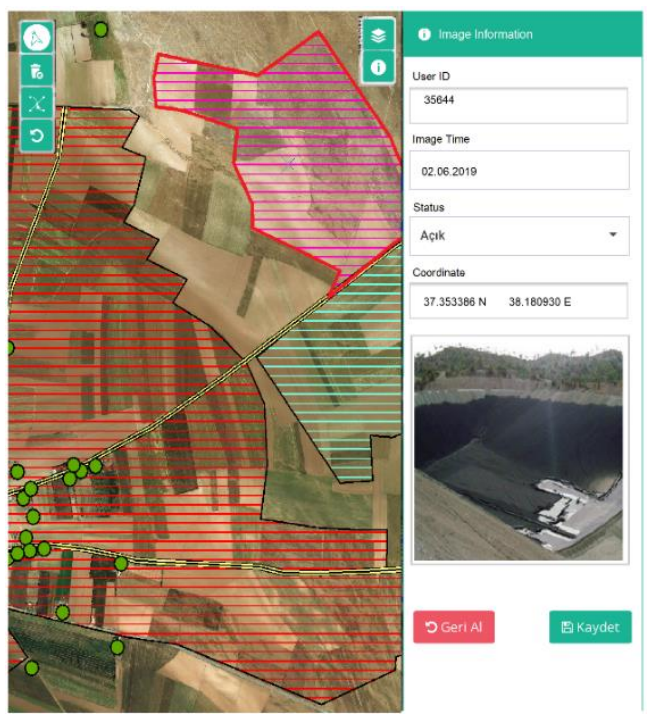

Figure 9. Displaying the information of the pictures in the program

\section{Results and discussion}

With this study, a mobile application for crowdsourcing geographic data generation was developed, and the geographic data were accessed by means of the developed application. Thus, a system was designed that allows users to obtain information about photos and data accuracy and consistency. With this system, efforts are made to solve the problem of data accuracy, which is frequently encountered in the crowdsourcing of geographic data production. The scheme of the designed system is presented in Figure 10.
In light of the information presented in Table 2, the following comments can be made about the geographic data obtained via crowdsourcing:

- The date the user took the photo and the date the data were entered can be compared. If these dates are the same, the information can be accepted as correct.

- The distance between the coordinates of the detailed information and the coordinates obtained from the photograph can be examined. If there is a certain difference in average picture-taking distance, such as 10-100 m, the information can be accepted as correct,

- It can be investigated whether there are differences between the camera's magnetic azimuth angle and the direction of the average picture-taking distance. If there is more than one difference, the consistency can be investigated.

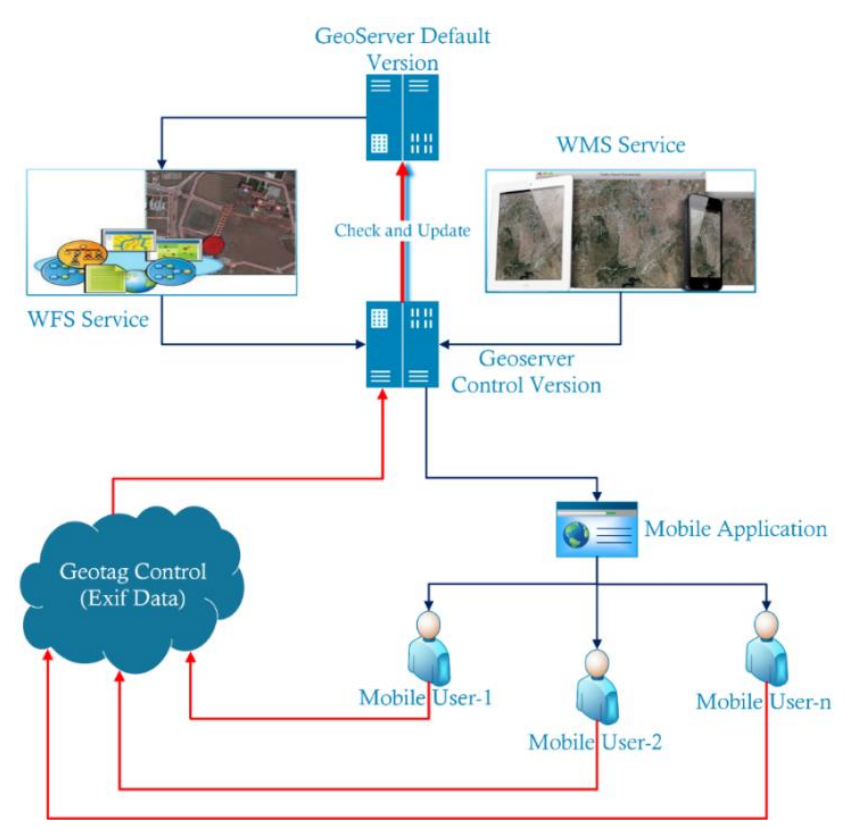

Figure 10. Recommended control system for crowdsourcing geographic data generation

\section{Conclusions}

Users who have access to the published WFS can make the necessary corrections by checking the information specified in the publication on-site. With these corrections, the post-activity practices given in the EIA report can be audited. With this audit, the administration in charge of the execution of the report will be able to effectively control the monitoring phase and respond quickly to any problems that may occur.

Transparency is one of the most widely criticized issues among the public in developing countries. In such countries, including Turkey, the supervision of the decisions made by the administration cannot be performed effectively by the public. This problem is frequently encountered in EIA projects. With this proposed system, public participation in environmental impact projects will be effectively ensured from the beginning to the end of the project. At the same time, the control responsibilities of the 
administration will be partially fulfilled through public participation, saving labor and time, as well as increasing the reliability of the practices carried out in the eyes of the people.

With this system developed, it is aimed to increase the effectiveness of the monitoring and control stages of the EIA project. Geographical data of the project published with the mobile application has reached many volunteer users. More than a thousand photos uploaded by these users to the system regarding the development of the project in different time periods were passed through the control procedures of the system and shared with the administration, which is responsible for monitoring and follow-up. In this way, the efficiency of the administration in the phases of project monitoring and control has been increased. At the same time, transparency and public participation to the EIA project, which is one of the important elements of EIA projects, has been ensured.

\section{Declaration of Conflicting Interests}

None of the authors of this paper has a financial or personal relationship with other people or organisations that could inappropriately influence or bias the content of the paper. No competing interests are at stake and there is no conflict of interest with other people or organisations that could inappropriately influence or bias the content of the paper.

The authors declared no potential conflicts of interest with respect to the research, authorship, and/or publication of this article.

\section{Funding}

The authors received no financial support for the research, authorship and/or publication of this article.

\section{References}

Abdelfattah M.A. and Kumar A.T. (2014), A web-based GIS enabled soil information system for the United Arabian Emirates and its applicability in agricultural land use planning, Arabian Journal of Geosciences, 8, 1813-1827.

Agapiou A., Lysandrou V., Alexakiis D., Themistocleous K., Cuca B., Argyriou A., Sarris A. and Hadjimitsis D. (2015), Cultural heritage management and monitoring using remote sensing data and GIS: The case study of paphos area, Environment and Urban Systems, 54, 230-239.

Anett U., Sebestyén V., Németh J., Yuzakova T. Diossy L., Domokos E., Sluser B., Redey A., Raduly I. and Raduly L. (2014), Advanced environmental impact assessment quantitative method for red mud disposal facilities, Environmental Engineering and Management Journal, 13, 2295-2300.

Annad O., Bendaoud A. and Goria S. (2017), Web information monitoring and crowdsourcing for promoting and enhancing the Algerian geoheritage, Arabian Journal of Geosciences., 10, 276-284.

Antoniou V. and Skopeliti A. (2015), Measures and Indicators of VGI Quality: An Overview, ISPRS Ann. Photogramm. Remote Sens. Spat. Inf. Sci., La Grande Motte, France, II-3/W5, 345351.

Ballatore A., Tahir A,. Mcardle G. and Bertolotto M. (2018), A comparison of open source geospatial technologies for web mapping, International Journal of Web Engineering and Technology, 6, 354-374.

Başaraner M. and Selçuk M. (2004), An Attempt to Automated Generalization of Buildings and Settlement Areas in Topographic Maps, Proceedings of XXth ISPRS Congress, Istanbul, Turkey, WG IV/3, 12-23.

Battersby S.E., Finn M.P., Usery E.L. and Yamamoto K.H. (2014), Implications of web mercator and its use in online mapping, Cartographica: The International Journal for Geographic Information and Geovisualization, 49, 85-101.

Borkowski B., Czajka I., Pluta M. and Suder-Dębska K. (2016), The conceptual design of dynamic acoustic maps to assess noise exposure, Polish Journal of Environmental Studies, 25(4), 1415-1420.

Budiu R. (2013), Mobile: Native apps, web apps and hybrid apps. On line at: http://www.nngroup.com/articles/mobile-nativeapps/.

Despotakis V.K. and Economopoulos A.P. (2007), A GIS model for landfill sitting, Global NEST Journal, 9(1), 29-34.

Dihkan M., Karsli F. and Guneroglu N. (2018), Evaluation of urban heat island effect in Turkey, Arabian Journal of Geosciences, 11, 186-206.

Ekin S. (2000), Problems faced and solution recommandaions in the environmental impact assessment aplications in Turkey, Master Thesis, Gazi University Graduate School of Sciences, Ankara, Turkey.

Ghodeif K.O., Arnous M.O. and Geriesh M.H. (2013), Define a protected buffer zone for Ismailia Canal, Egypt using geographic information systems, Arabian Journal of Geosciences, 6, 43-53.

Gökalp S.S. (2020) Environmental Administration in Turkey, In: Environmental Law and Policies in Turkey, Savaşan Z., Sümer V. (Eds), The Anthropocene: Politic-Economics-SocietyScience, Vol 31. Springer, Cham, 55-82.

Goodchild M.F. (2007), Citizens as sensors: the world of volunteered geography, GeoJournal, 69, 211-221.

Goodchild M.F. and Li L. (2012), Assuring the quality of volunteered geographic information, Spatial Statistic, 1, 110120.

Hanson E. and Wolff E. (2010), Change Detection for Update of Topographic Databases through Multi-Level Region-Based Classification of VHR Optical and SAR Data, GEOBIA 2010: Geograpich Object-Based Image Analysis, Ghent, Belgium, Vol. XXXVIII-4/C7, 26-32.

Hidalgo-Ruz V. and Thiel M. (2015), The contribution of citizen scientists to the monitoring of marine litter, Marine Anthropogenic Litter, 16, 429-447.

Howe J. (2006), The rise of crowdsourcing, Wired Magazine, 14(6), 1-4.

İşcan F. and Ilgaz A. (2017), Analysis of geographic/urban information system web presentations of local governments in Turkey, International Journal of Engineering and Geosciencesences, 2(3), 75-83.

ISO. (2013), International organization for standardization 19157:2013, Geographicinformation - Data quality, On line at: http://www.iso.org/iso/iso_catalogue/catalogue_tc/catal ogue_detail.htm? csnumber=32575

Landeta P., Vásquez J., Rea X. and García-Santillán I. (2019), Edition, Publication and Visualization of Geoservices Using Open-Source Tools, In: Information and Communication Technologies of Ecuador, Botto M., Barba-Maggi L., González- 
Huerta J. and Villacrés-Cevallos P. (Eds.), Springer International Publishing, USA, 266-280.

Mouratidis I., Dimopoulos G., Astaras T. and Savvidis S. (2010) Sustainable water resources management through the use of GIS technologies, Global NEST Journal, 12(2), 140-151.

Müller S. and Heipke C. (2009), Object-Based Verificationand Update of a Large-Scale Topographic Database, ISPRS (International Society for Photogrammetry and Remote Sensing) Workshop, ISPRS Commission IV, WG IV/2, Hanover, Germany.

Önder M. (2000), Remote Sensing in Geographical Information Systems, Printing House of Hacettepe University, Ankara, 3677.

Pang J. and Liu Z. (2016), Motivation system of crowdsourcing community from a supply chain perspective, Mathematical Problems in Engineering, 1-9.

Peker N. (1996), Establishing checklist and evaluation matrices that can be used in EIA reports for some types of activities, Master Thesis, Çukurova University Graduate School of Sciences, Adana.

Persada S.F., Lin S.C., Nadlifatin R. and Razif M. (2015), Investigating the citizens' intention level in environmental impact assessment participation through an extended theory of planned behavior model, Global NEST Journal, 17(4), 847857.

Raymond S.E. and O'reilly T. (1999), The Cathedral and the Bazaar, O'Reilly \& Associates Inc., O'Reilly T. and Shangraw S.J. (Eds), Sebastopol, USA, 10-49.

Sivrikaya F., Başkent E., Sevik U., Akgül C., Kadiogullari A. and Değermenci A. (2010), A gis-based decision support system for forest management plans in Turkey, Environmental Engineering and Management Journal, 9, 929-937.

Sloane P. (2011), A Guide to Open Innovation and Crowdsourcing, Koganpage Limited, Londra, England. pp. 19-21.

Sluser B., Jitar O., Teodosiu C., Strungaru Ș., Nicoara M. and Plavan G. (2015), Environmental impact and risk assessment of the main pollution sources from the Romanian black sea coast, Environmental Engineering and Management Journal, 14, 331-340.

Strobl C. (2016), PostGis, In: Encyclopedia of GIS, Shekhar S., Xiong H., Zhou X. (Eds) Springer Nature, USA, 36-95.

Vretanos P.A. (2005), Web feature service implementation specification, version 1.1.0, Open Geospatial Consortium Inc., OGC:04094, On line at: https://portal.opengeospatial.org/files/? artifact_id=8339

Wang S., Shang M., Zhou Y., Liu W., Wang F. and Wang L. (2017), Resources and environmental carrying capacity using RS and GIS, Polish Journal of Environmental Studies, 26(6), 27932800.

Weibel R. and Dutton G. (1998), Constraints-Based Automated Map Generalization, Proceedings of 8th International Symposium on Spatial Data Handling (SDH'98), Vancouver, 214-224.

Yıldırım V., Yomralıoğlu T., Nişancı R., Çolak E.H., Bediroğlu S. and Memişoğlu T. (2016), An integrated spatial method for minimizing environmental damage of transmission pipelines, Polish Journal of Environmental Studies, 25(6), 2653-2563.

Yıldız F. and Kahveci M. (2010), Positioning Systems with GPS/GNSS Satellites Theory and Practice Book, Nobel Publications, 3, Ankara, Turkey. 